\title{
Early and maintained response levels in psoriasis patients treated with tildrakizumab
}

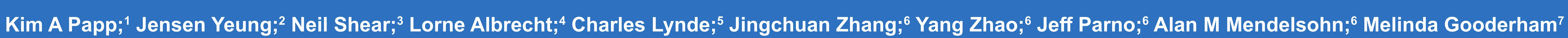

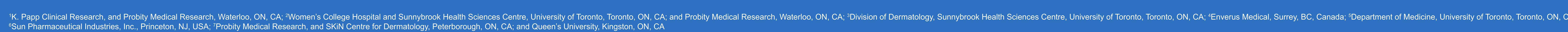

\section{INTRODUCTION}

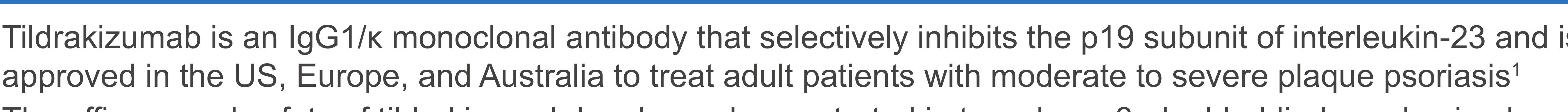

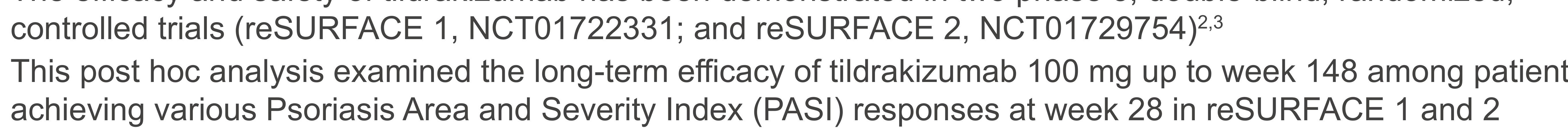
METHODS

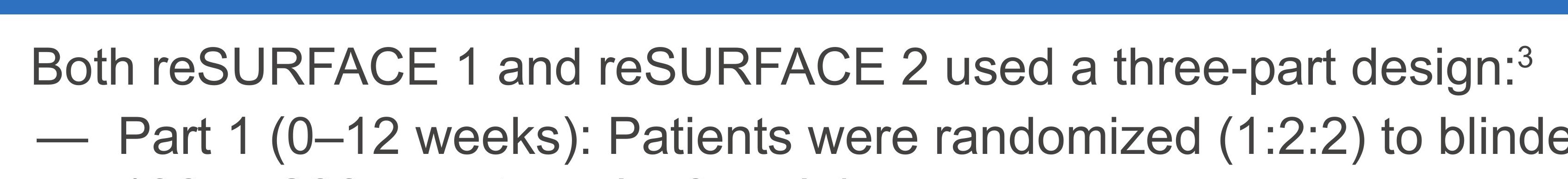

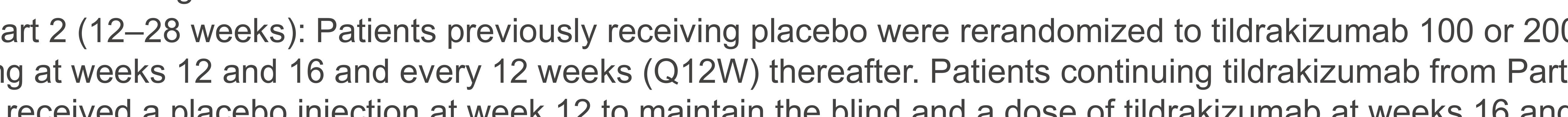

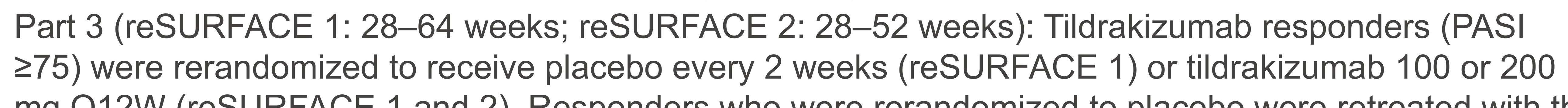

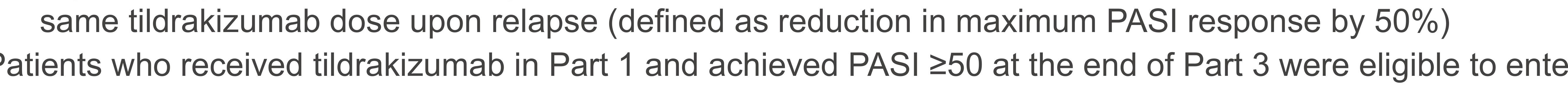

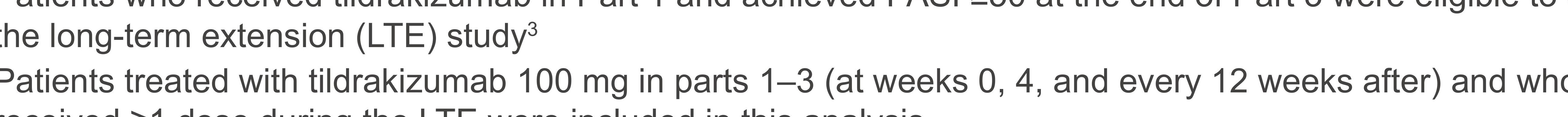

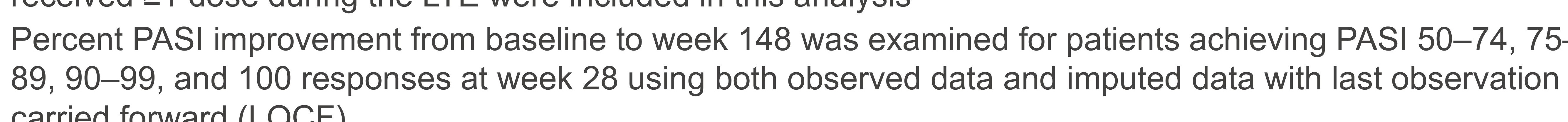

RESULTS
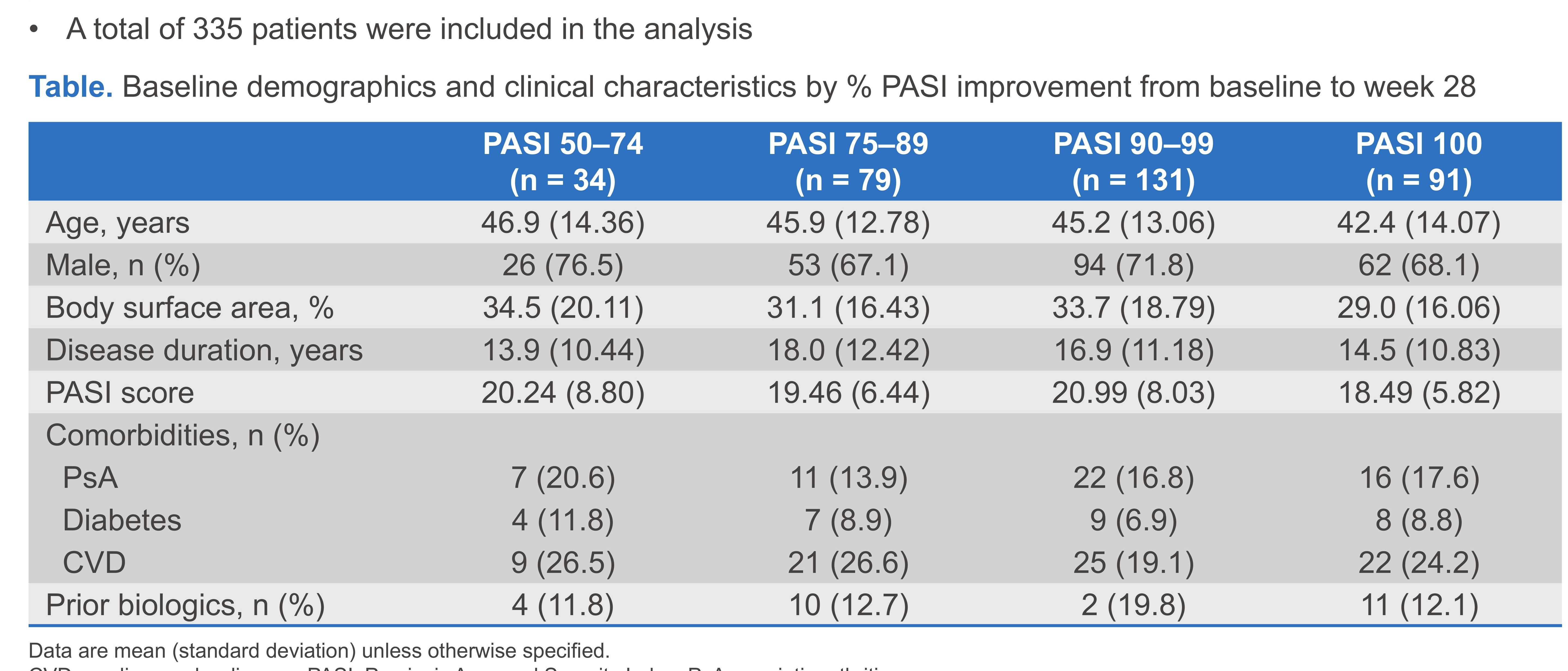

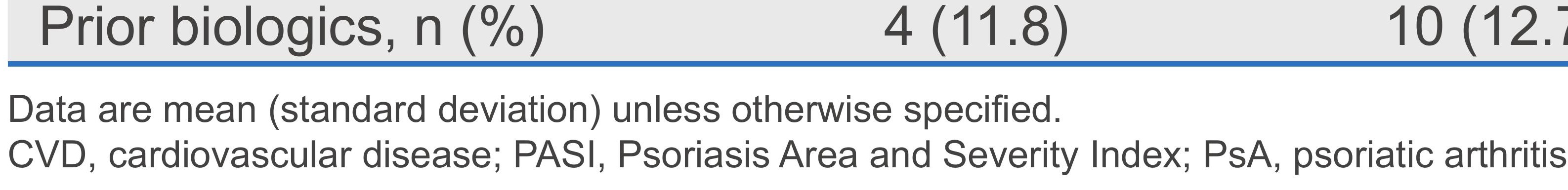

- Patients had longstanding psoriasis (mean 16.1 years), but 85.2\% had not previously been treated with a

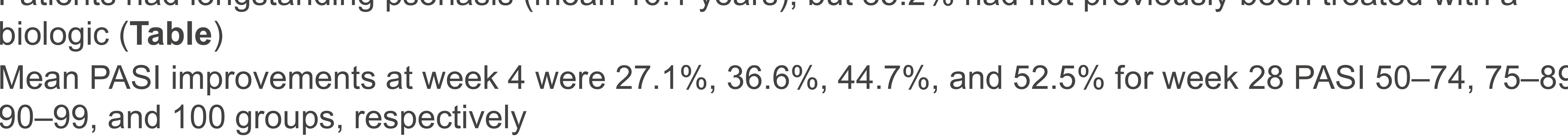

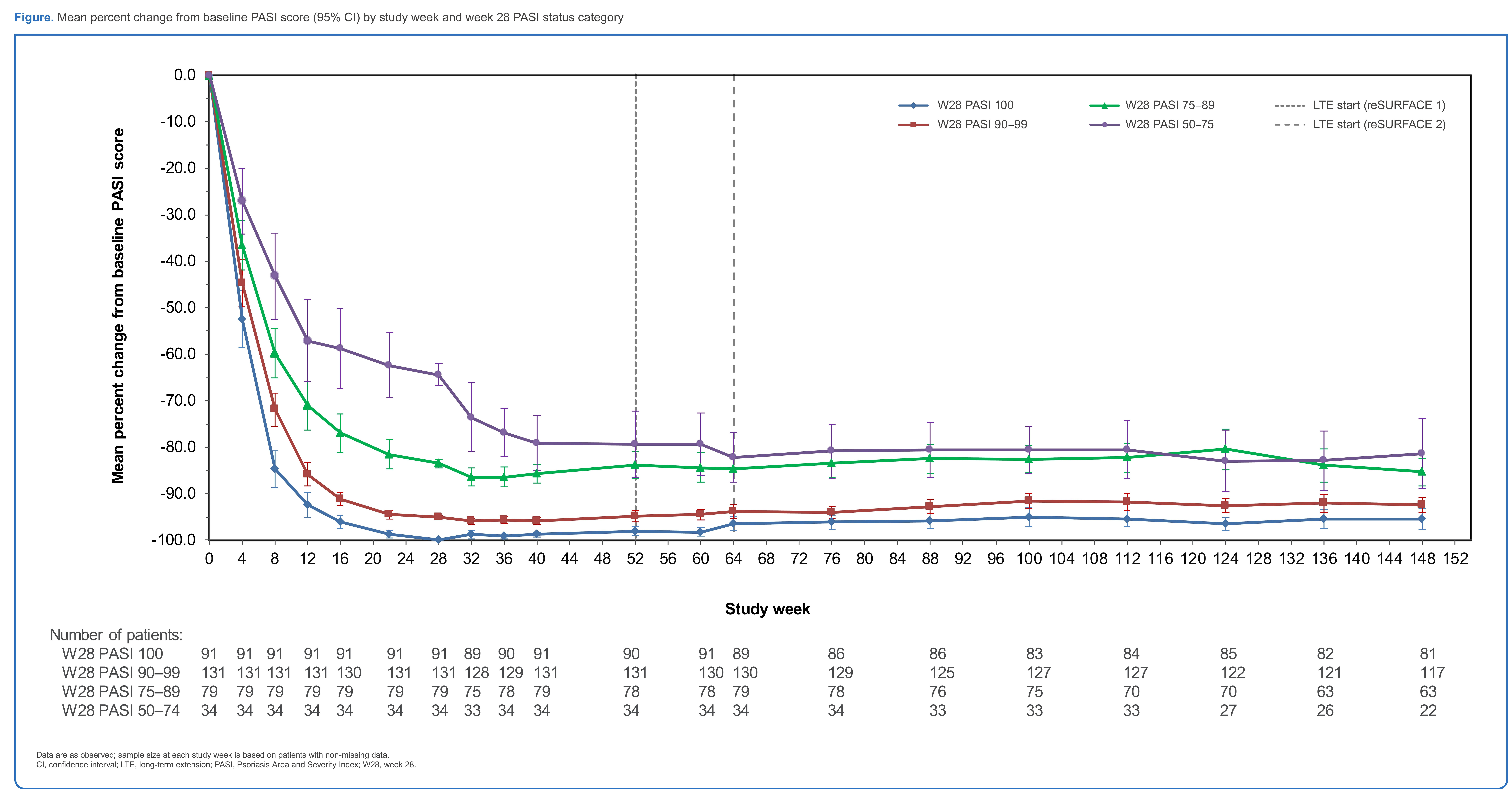

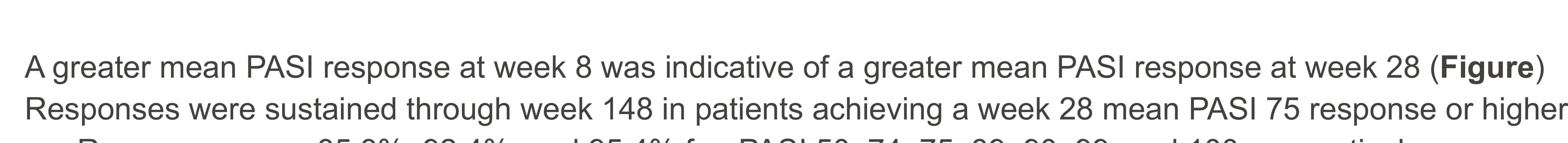

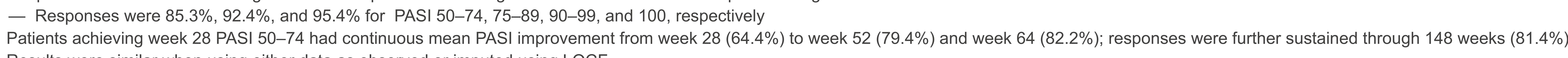

DISCUSSION

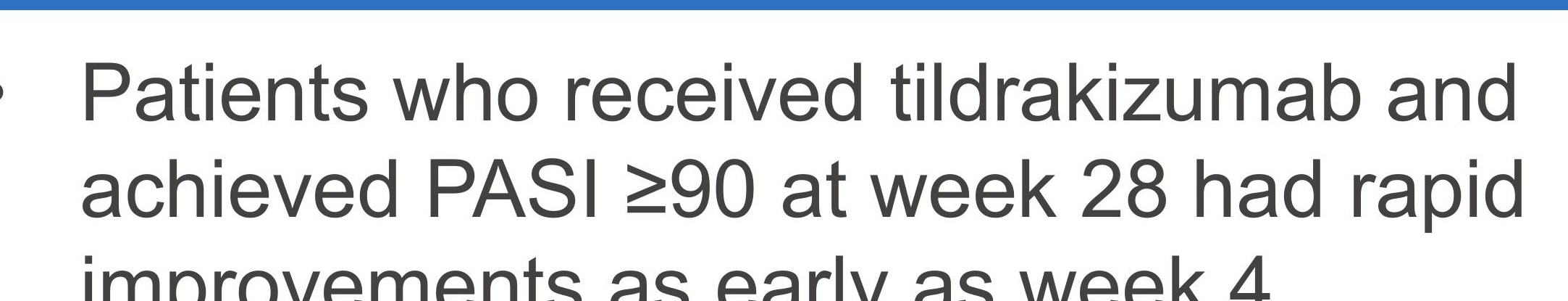

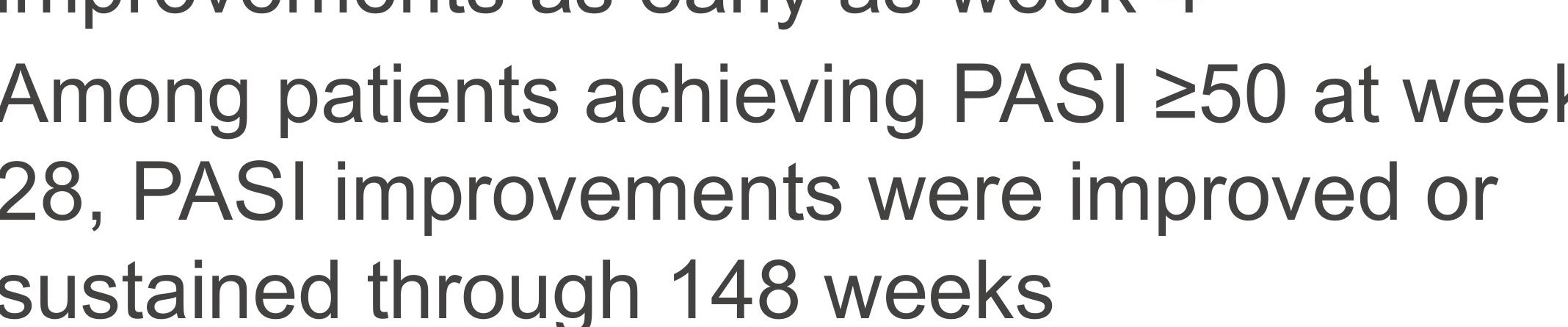

REFERENCES

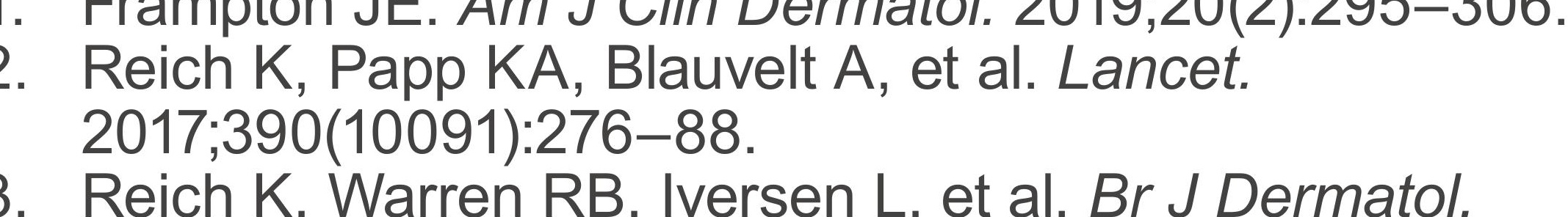

ACKNOWLEDGMENTS

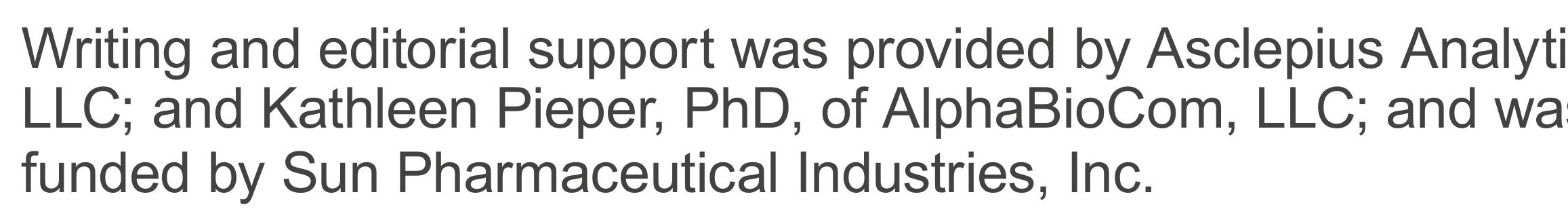

DISCLOSURES

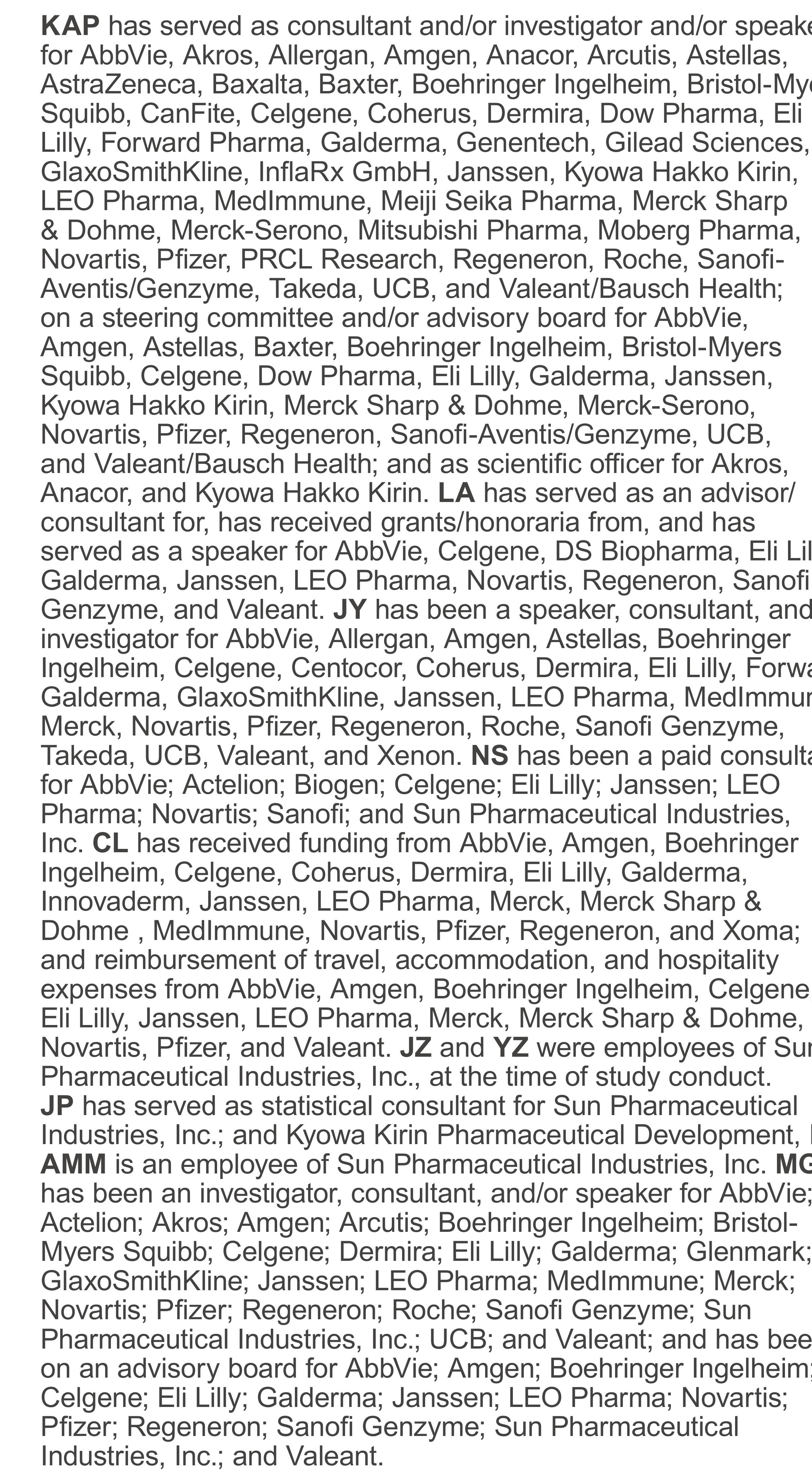

